\title{
Hydroxide catalysis bonding of silicon carbide
}

\author{
A.A. van Veggel ${ }^{\mathrm{c}, *}$, D. van den Ende ${ }^{\mathrm{b}}, \mathrm{J}_{\text {. Bogenstahl }}{ }^{\mathrm{c}}$, S. Rowan ${ }^{\mathrm{c}}$, \\ W. Cunningham ${ }^{\text {c }}$, G.H.M. Gubbels ${ }^{b}$, H. Nijmeijer ${ }^{\mathrm{a}}$ \\ ${ }^{a}$ Department of Mechanical Engineering, Eindhoven University of Technology, Den Dolech 2, 5612 AZ Eindhoven, The Netherlands \\ ${ }^{\mathrm{b}}$ TNO Science and Industry, De Rondom 1, 5612 AP Eindhoven, The Netherlands \\ ${ }^{\mathrm{c}}$ Institute for Gravitational Research, University of Glasgow, Glasgow G12 8QQ, Scotland, UK
}

Received 3 March 2007; received in revised form 29 May 2007; accepted 2 June 2007

Available online 30 July 2007

\begin{abstract}
For bonding silicon carbide optics, which require extreme stability, hydroxide catalysis bonding is considered [Rowan, S., Hough, J. and Elliffe, E., Silicon carbide bonding. UK Patent 0407953.9 , 2004. Please contact Mr. D. Whiteford for further information: D.Whiteford@admin.gla.ac.uk]. This technique is already used for bonding silicate-based materials, like fused silica and Zerodur. In application with silicon carbide, the technique is highly experimental and the aim is to test the strength of the bond with silicon carbide. The silicon carbide is polished to $\lambda / 10 \mathrm{PV}$ flatness and then oxidized at $1100{ }^{\circ} \mathrm{C}$ in a wet environment prior to bonding to form a necessary layer of $\mathrm{SiO}_{2}$ on the surface. The bonding is performed in clean room conditions. After bonding the pieces are sawed into bars to determine the strength in a four-point bending experiment. The oxidization process shows many different color changes indicating thickness variations and contamination of the oxidization process. The bonding has been performed with success. However, these bonds are not resistant against aqueous cooling fluids, which are used during sawing. Several bars have survived the sawing and a maximum strength of $30 \mathrm{~N} \mathrm{~mm}^{-2}$ has been measured.
\end{abstract}

(C) 2007 Elsevier Ltd. All rights reserved.

Keywords: Hydroxide catalysis bonding; Joining; Strength; SiC

\section{Introduction}

Silicon carbide ( $\mathrm{SiC}$ ) has been used for structural applications since the 1960s. Because of its excellent performance in extreme conditions such involving abrasion, corrosion and high temperatures, it is now applied for fire bricks, heating elements and tubes, brake discs and seal rings for water pumps. ${ }^{2}$

In parallel with high temperature applications, the interest in $\mathrm{SiC}$ for application in completely different extreme environments is growing, e.g. in the space and semi-conductor industries. These applications require extreme shape stability in vacuum (and possibly cryogenic) environments. In the space industry the main applications have been for mirrors and some support structures for those mirrors. Examples of $\mathrm{SiC}$ mirrors that are already in an Earth orbit are the Narrow Angle Camera of Rosetta and mirrors for Rocsat $2 .{ }^{3}$ GAIA is a future mission of which nearly the entire payload will be constructed of $\mathrm{SiC}^{4}$ The payload will contain a laser metrology system, which con-

\footnotetext{
* Corresponding author.

E-mail address: m.veggel@ physics.gla.ac.uk (A.A. van Veggel).
}

sists of a number of $\mathrm{SiC}$ optical components, mounted onto a $\mathrm{SiC}$ optical bench. The positional stability required of the optical components relative to each other is $0.19 \mathrm{pm}$ over a period of $6 \mathrm{~h}$. This requires a joining technique for $\mathrm{SiC}$ that does not introduce stresses and is very stable. Hydroxide catalysis bonding can be of interest for this specific application. ${ }^{1}$

Hydroxide catalysis bonding or 'silicate' bonding is a bonding technique invented and patented by $\mathrm{Gwo}^{5,6}$ at Stanford University. The technique has been used in the Gravity Probe B space experiment (successfully launched in 2004). The technique has been applied by the Institute of Gravitational Research at the University of Glasgow in the GEO 600 gravitational wave detector $^{7}$ and will be applied on the LISA Technology Package interferometer for LISA pathfinder. ${ }^{8-10}$ It has however not thoroughly investigated for bonding $\mathrm{SiC}$.

The goals of the hydroxide catalysis bonding experiments which are discussed in this paper were threefold:

- gain experience in polishing $\mathrm{SiC}$ to $\lambda / 10 \mathrm{PV}$ flatness;

- gain experience in bonding $\mathrm{SiC}$ with the hydroxide catalysis bonding technique; and 
- determine the strength of the $\mathrm{SiC}-\mathrm{SiC}$ hydroxide catalysis bonds in air at ambient temperature.

The main focus however, is on gaining experience in bonding $\mathrm{SiC}$.

\section{Hydroxide catalysis bonding technique}

The hydroxide catalysis bonding technique is a technique that achieves bonding between a number of materials if a silicate-like network can be created between the surfaces, or in other words any silica containing material. Examples are silica, Zerodur, fused silica, ULE glass and granite.

The two silicate-based materials are bonded using an alkaline bonding solution: like sodium hydroxide $(\mathrm{NaOH})$, potassium hydroxide $(\mathrm{KOH})$ and sodium silicate $\left(\mathrm{Na}_{2} \mathrm{SiO}_{3}\right)$ dissolved in water.

The bonding surfaces must have a peak-to-valley (PV) flatness of $\leq 60 \mathrm{~nm}$ if a hydroxide solution is used. Both bonding surfaces are cleaned in a clean environment to be free of chemical and particulate contaminants. The bonding solution is filtered and dispensed on the bonding surface with a volume of $\geq 0.4 \mu \mathrm{l} / \mathrm{cm}^{2}$. The other substrate is then placed gently on top of the substrate with the bonding solution and can be compressed slightly to ensure a uniform bond. At this moment the hydroxide catalysis commences and consists of three steps ${ }^{5}$ :

1. Hydration and etching: in which the $\mathrm{OH}^{-}$ions in the bonding solution act as a catalyst and etch the silica surfaces in contact. This causes the liberation of silicate ions:

$$
\mathrm{SiO}_{2}+\mathrm{OH}^{-}+2 \mathrm{H}_{2} \mathrm{O} \rightarrow \mathrm{Si}(\mathrm{OH})_{5}^{-}
$$

2. Polymerization: due to the hydration the active number of $\mathrm{OH}^{-}$ions reduces and the $\mathrm{pH}$ of the solution decreases. If the $\mathrm{pH}<11$, the silicate ions dissociate:

$$
\mathrm{Si}(\mathrm{OH})_{5}{ }^{-} \rightarrow \mathrm{Si}(\mathrm{OH})_{4}+\mathrm{OH}^{-}
$$

And siloxane chains and water are formed:

$$
2 \mathrm{Si}(\mathrm{OH})_{4} \rightarrow(\mathrm{HO})_{3} \mathrm{SiOSi}(\mathrm{OH})_{3}+\mathrm{H}_{2} \mathrm{O}
$$

Once the siloxane chains are formed the bond is rigid.

3. Dehydration: in which the water migrates or evaporates. After 4 weeks of curing at room temperature full strength is achieved.

The time taken for a bond to form can be controlled by a combination of temperature and $\mathrm{pH}$ of the bonding solution used. ${ }^{11}$ The bonding thickness is approximately $50 \mathrm{~nm}$. The roughness is not an issue. The roughness can even be $0.5 \mu \mathrm{m}$ to avoid optical contacting during alignment.

$\mathrm{SiC}$ cannot be used directly for hydroxide catalysis bonding. During polishing to $\lambda / 10 \mathrm{PV}$ flatness, any $\mathrm{SiO}_{2}$ layer formed during sintering is removed. To make bonding of to SiC components possible, the surface must have a thin layer of $\mathrm{SiO}_{2}$. This layer is formed after cleaning the $\mathrm{SiC}$ pieces and then placing the

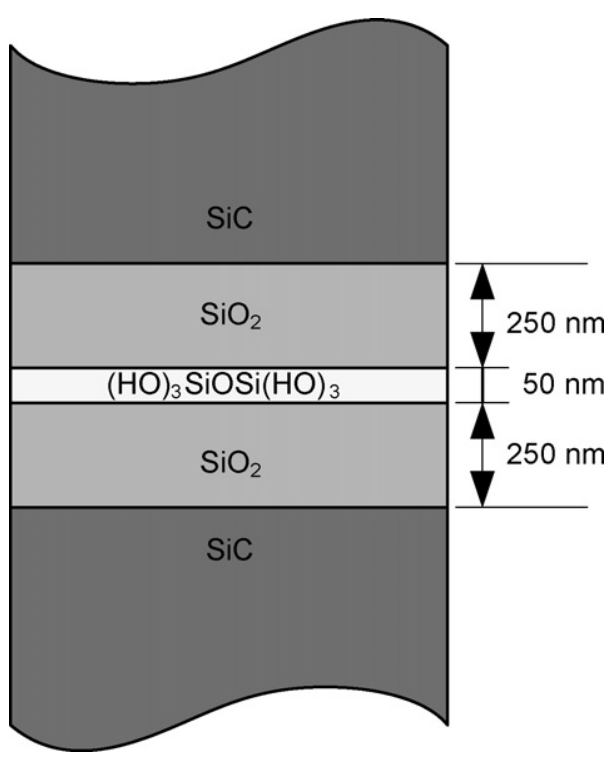

Fig. 1. Layer structure of hydroxide catalysis bonded SiC pieces.

pieces in a quartz tube furnace at $1100^{\circ} \mathrm{C}$ in a wet nitrogen environment. The $\mathrm{SiO}_{2}$ layer thickness must be smaller than $250 \mathrm{~nm}$ to maintain the $\lambda / 10 \mathrm{PV}$ flatness.

The layered structure of hydroxide catalysis bonded $\mathrm{SiC}$ pieces is shown in Fig. 1.

\section{Approach}

The hydroxide catalysis bonding experiments consisted of seven steps, each of which is discussed in this section:

- sawing SiC blocks;

- polishing the SiC blocks;

- oxidization of the SiC blocks;

- hydroxide catalysis bonding of the SiC blocks;

- sawing bars from the bonded SiC blocks;

- viewing bonds under the scanning electron microscope (SEM); and

- four-point bending experiments on $\mathrm{SiC}$ bars.

\subsection{Sawing SiC blocks}

First, blocks were sawed from three different types of $\mathrm{SiC}$ (Boostec SSiC with and without CVD SiC coating, Xycarb C/SiC with CVD SiC coating and Hexoloy SA SSiC without $\mathrm{SiC}$ coating). For a representative measurement of the bending strength at least 25 bars/material should be tested, such that a reliable statistical analysis can be performed. Because the HCB technique is an experimental technique as well, enough surface area had to be bonded to make 50 bars. The dimensions of the blocks are shown in Table 1.

\subsection{Polishing SiC blocks}

The bonding surfaces were polished to $\lambda / 10$ PV flatness. To achieve this flatness, the blocks of Boostec material and Xycarb 
Table 1

Dimensions of the blocks

\begin{tabular}{|c|c|c|c|c|}
\hline Material & Number of blocks & $h(\mathrm{~mm})$ & $b(\mathrm{~mm})$ & $(1 / 2) l(\mathrm{~mm})$ \\
\hline Boostec SSiC + CVD SiC & 8 & $35.0 \pm 0.2$ & $10.5 \pm 0.2$ & $22.5 \pm 0.2$ \\
\hline Boostec SSiC + CVD SiC & 8 & $35.0 \pm 0.2$ & $10.5 \pm 0.2$ & $22.5 \pm 0.2$ \\
\hline Boostec SSiC & 8 & $35.0 \pm 0.2$ & $10.5 \pm 0.2$ & $22.5 \pm 0.2$ \\
\hline Boostec SSiC & 8 & $35.0 \pm 0.2$ & $10.5 \pm 0.2$ & $22.5 \pm 0.2$ \\
\hline Xycarb C/SiC + CVD SiC & 8 & $35.0 \pm 0.2$ & $10.5 \pm 0.2$ & $22.5 \pm 0.2$ \\
\hline Hexoloy SSiC & 6 & \multicolumn{2}{|c|}{6 equal $( \pm 0.5 \mathrm{~mm})$ wedges from a $\emptyset 76 \mathrm{~mm}$ disc } & $13.0 \pm 0.2$ \\
\hline
\end{tabular}

material were bonded with an adhesive onto one pan as shown in Fig. 2a. The Hexoloy blocks already formed a ring, and were polished on a separate pan (Fig. 2b). The polishing was conducted with $3 \mu \mathrm{m}$ diamond powder type $\mathrm{O}$ of Kemet on a siphon machine with 38 rotations $/ \mathrm{min}$ and $3 \mathrm{~kg}$ load for $80 \mathrm{~h}$.

\subsection{Oxidization of SiC blocks}

After ultrasonic cleaning in an acetone bath, the blocks were oxidized in a quartz tube oven at $1100^{\circ} \mathrm{C}$ in an oxygen deficient environment. This environment was created by bubbling zero-

(a)

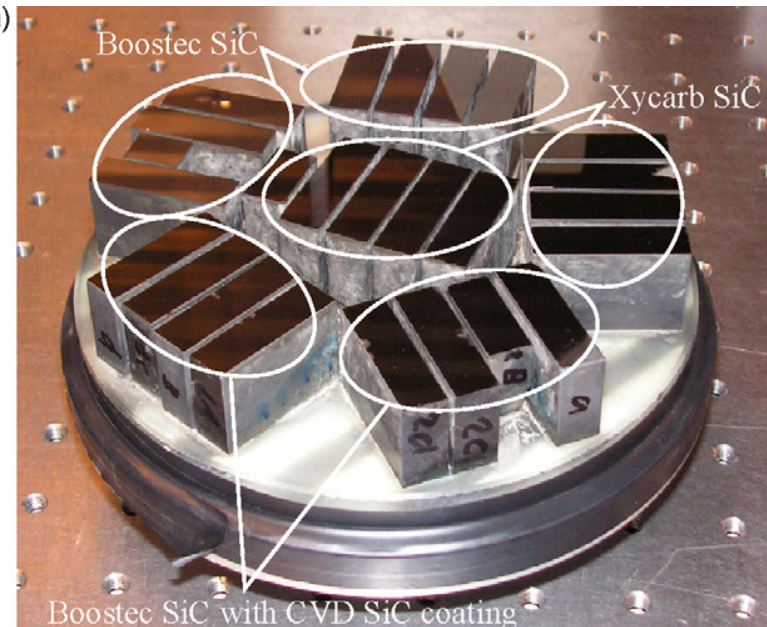

(b)

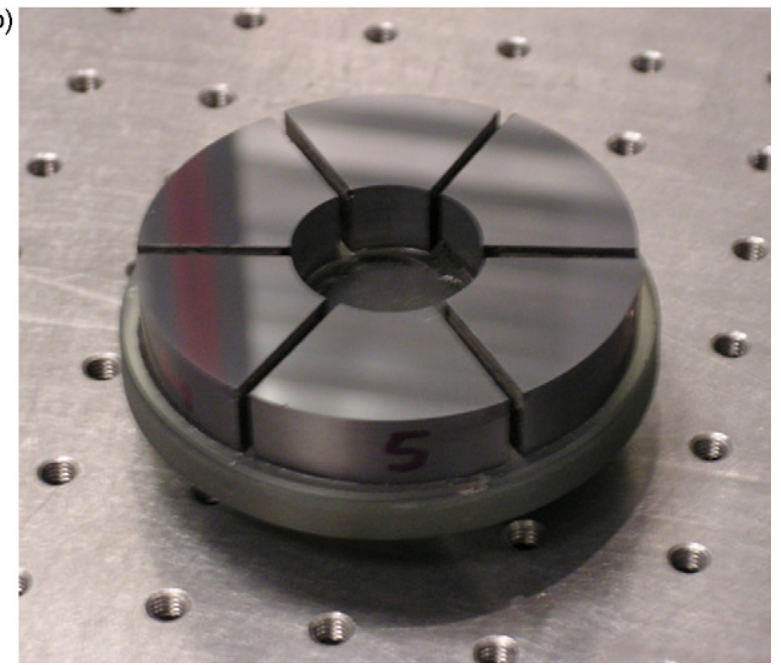

Fig. 2. Polishing pans with (a) Boostec and Xycarb SiC and with (b) Hexoloy $\mathrm{SiC}$

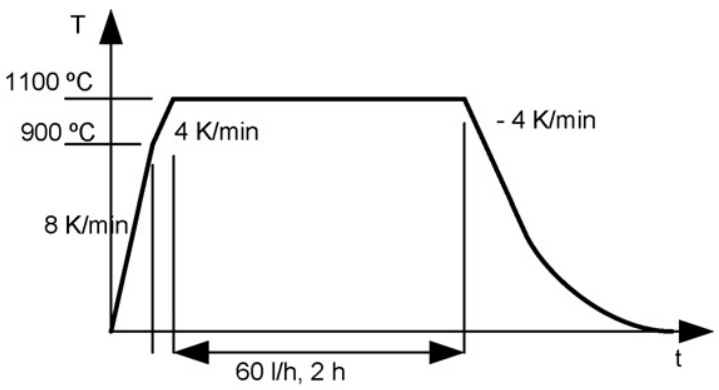

Fig. 3. Oxidization temperature scheme.

grade nitrogen through demineralised water at $80^{\circ} \mathrm{C}$. This wet nitrogen mixture was pumped through the oven. The oven heating scheme is shown in Fig. 3. The bubbling was initiated slowly at $900{ }^{\circ} \mathrm{C}$. At $1100{ }^{\circ} \mathrm{C}$ the flow is increased to $60 \mathrm{l} / \mathrm{h}$. This flow level and temperature was maintained for $2 \mathrm{~h}$. The oxidization set-up is shown in Fig. 4.

\subsection{HCB bonding}

The blocks were bonded using the HCB technique. Prior to bonding the blocks were thoroughly cleaned with cerium oxide and sodium bicarbonate powder in de-ionised water to make the bonding surfaces hydrophilic. The bonding was performed in clean room conditions by mixing a sodium silicate solution $\left(14 \% \mathrm{NaOH}\right.$ and $\left.27 \% \mathrm{SiO}_{2}\right)$ with de-ionised water with a volume ratio 1:6. The bonding solution was applied in the volume of $0.4 \mu \mathrm{l} / \mathrm{cm}^{2}$ to one of the bonding surfaces upon which the other bonding surface was placed. The sodium silicate, the water

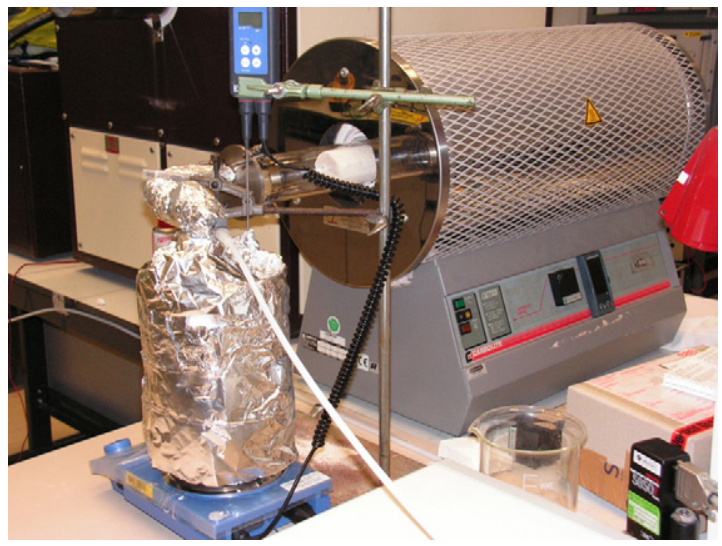

Fig. 4. Oxidization set-up. 


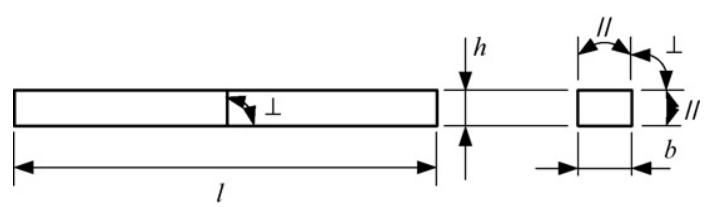

Fig. 5. Dimensions of a bar.

and the silicon oxide on the bonding surfaces immediately form siloxane chains bonding the two surfaces together. The bonds were made partly at the University of Glasgow, Department of Astronomy and Physics. The other bonds were made at TNO Science and Industry in Eindhoven. The bonds were cured in air for 3 weeks, 1 week of which the bonds were held at $50^{\circ} \mathrm{C}$.

\subsection{Sawing bars}

The blocks were sawed and ground into bars, such that the HCB bond was in the centre as shown in Fig. 5. The desired dimensions of the bars for each material are shown in Table 2 . However, the final dimensions were dependent on the success during sawing.

\subsection{Viewing bonds with the SEM}

The bonds were inspected under the SEM after sawing to assess the $\mathrm{SiO}_{2}$ layer thicknesses and the $\mathrm{HCB}$ bonding thickness.

\subsection{Four-point bending experiments}

The bars were subjected to a four-point bending experiment according to ASTM norm C1161-2C. ${ }^{12}$ A schematic illustration of a four-point bending set-up is shown in Fig. 6 .

The ASTM norm is focused on determining the bending strength of ceramic materials. In the four-point bending experiment the force $F$ was increased slowly with prescribed crosshead speed of $0.55 \mathrm{~mm} / \mathrm{min}$. The applied force and crosshead speed were measured. Between the upper two rods the moment along the bar is constant, and thus the stresses over distance $L / 2$. The maximum stress upon fracture during the bending experiment was calculated using ${ }^{12}$

$\sigma_{\max }=\frac{3 F L}{4 b h^{2}}$

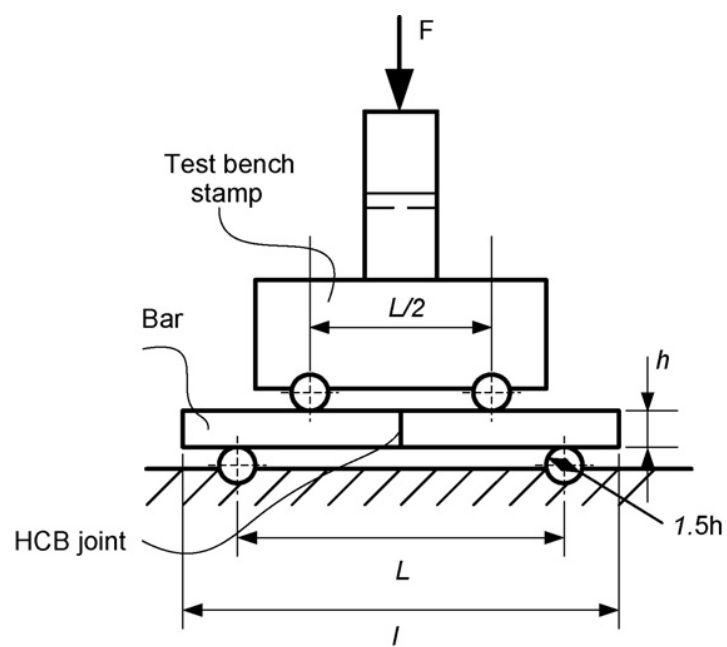

Fig. 6. Schematic representation of the four-point bending set-up.

\section{Results}

For all experimental steps, the results and observations are discussed in this section.

\subsection{Polishing the blocks}

After polishing for 1.5 weeks the required flatness of $\lambda / 10$ PV or 0.1 waves was obtained for all Hexoloy blocks and all but one Xycarb blocks. The flatness achieved for the Boostec blocks was in most cases worse than 0.1 wave (Table 3). The largest deformation of the surfaces was seen at the long edges of the polished surfaces. The surfaces of Boostec SSiC and Xycarb $\mathrm{C} / \mathrm{SiC}$ are generally convex.

The Xycarb blocks mounted in the centre were slightly flatter on average than the Xycarb blocks on the outer part of polishing pan.

\subsection{Oxidization}

The blocks were oxidized in four sessions. In the first two sessions the coloration of the polished surface due to oxidization showed a dependency of the position in the oven. In the front of the wet air flow the discoloration is less than further in the flow. This has, however, not been observed in the last two sessions.

In the first two sessions, the color change of the Xycarb and Hexoloy blocks was yellow (Fig. 7a) and the color change of Boostec material was increasingly orange to blue (Fig. 7b). However, in the last two sessions the discoloration of all materials varied from yellow to purple to blue. Some blocks showed smalls

Table 2

Bars with dimensions and tolerances according to the ASTM norm (use Fig. 5 for understanding of the symbols)

\begin{tabular}{lllll}
\hline Material & $h(\mathrm{~mm})$ & $b(\mathrm{~mm})$ & $l(\mathrm{~mm})$ & $\perp(\mathrm{mm})$ \\
\hline Boostec + CVD & $3.00 \pm 0.13$ & $4.00 \pm 0.13$ & 45 & 0.015 \\
Boostec & $3.00 \pm 0.13$ & $4.00 \pm 0.13$ & 45 & 0.015 \\
Xycarb + CVD & $3.00 \pm 0.13$ & $4.00 \pm 0.13$ & 45 & 0.015 \\
Hexoloy & $1.58 \pm 0.07$ & $2.1 \pm 0.07$ & 26 & 0.015 \\
\hline
\end{tabular}


Table 3

Measured flatness in waves

\begin{tabular}{|c|c|c|}
\hline Block & Overall flatness (waves) & $<0.110$ wave? \\
\hline \multicolumn{3}{|c|}{ Boostec SSiC + CVD SiC } \\
\hline UAcvd1 & 0.119 & No \\
\hline UAcvd2 & 0.077 & Yes \\
\hline UAcvd3 & 0.164 & No \\
\hline UAcvd4 & 0.159 & No \\
\hline UAcvd5 & 0.130 & No \\
\hline UAcvd6 & 0.089 & Yes \\
\hline UAcvd7 & 0.103 & Yes \\
\hline UAcvd8 & 0.148 & No \\
\hline \multicolumn{3}{|c|}{ Boostec SSiC } \\
\hline UA1 & 0.127 & No \\
\hline UA2 & 0.088 & Yes \\
\hline UA3 & 0.161 & No \\
\hline UA4 & 0.151 & No \\
\hline UA5 & 0.152 & No \\
\hline UA6 & 0.095 & Yes \\
\hline UA7 & 0.134 & No \\
\hline UA8 & 0.155 & No \\
\hline \multicolumn{3}{|c|}{ Xycarb C/SiC + CVD SiC } \\
\hline UB1 & 0.105 & Yes \\
\hline UB2 & 0.088 & Yes \\
\hline UB3 & 0.061 & Yes \\
\hline UB4 & 0.096 & Yes \\
\hline UB5 & 0.115 & No \\
\hline UB6 & 0.109 & Yes \\
\hline UB7 & 0.076 & Yes \\
\hline UB8 & 0.104 & Yes \\
\hline \multicolumn{3}{|c|}{ Hexoloy SSiC } \\
\hline UC1 & 0.098 & Yes \\
\hline $\mathrm{UC} 2$ & 0.099 & Yes \\
\hline UC3 & 0.097 & Yes \\
\hline UC4 & 0.092 & Yes \\
\hline UC5 & 0.099 & Yes \\
\hline UC6 & 0.098 & Yes \\
\hline
\end{tabular}

spots of different color (Fig. 7b). The Hexoloy blocks showed the most uniform color changes (Fig. 7c). Finally, marker residuals to indicate the nonflat parts of the reflective surface, which have visually been removed during cleaning, became visible again after oxidization (Fig. 7d).

\subsection{Bonding the blocks}

Of each material, one half was bonded in Glasgow and the other half was bonded in Eindhoven in the interest of transfer of knowledge from the University of Glasgow to TNO in Eindhoven. The bonding has been performed successfully for 13 of 15 bonds. The two remaining bonds (both made in Eindhoven) proved unsuccessful after 3 weeks curing (Table 4). The failure of these bonds was attributed to dust and a hair on the bonding surface, which prevented good bonding. There were some small differences between the bonding in Glasgow and Eindhoven:

- In Glasgow, the blocks were kept wet after cleaning and have been wiped with methanol just before bonding because they had to be transported from a cleaning facility to a clean room facility. In Eindhoven, the blocks were cleaned in clean room (a)
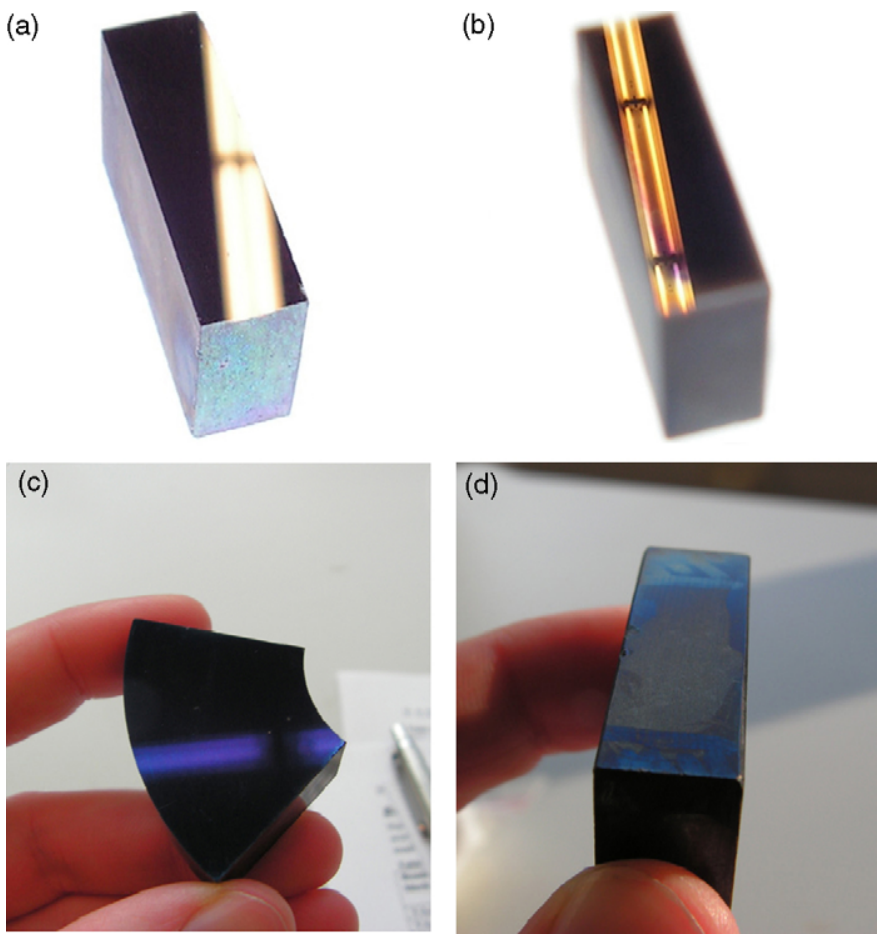

Fig. 7. Some examples of oxidized blocks (a) yellow on Xycarb $\mathrm{C} / \mathrm{SiC}$ with CVD SiC, (b) orange to purple on Boostec SSiC with CVD SiC, (c) uniform blue on Hexoloy SSiC and (d) marker residuals on Boostec SSiC with CVD SiC. (For interpretation of the references to color in this figure legend, the reader is referred to the web version of the article.)

conditions and have been blown dry with clean air. The blocks have not been wiped with methanol.

- In Glasgow, the bonding solution was filtered. In Eindhoven the bonding solution was not filtered because filters were unavailable.

- In Glasgow the bonds were made with exactly $1.4 \mu \mathrm{l}$ bonding solution for the Boostec and Xycarb blocks and with $2.4 \mu \mathrm{l}$ for the Hexoloy blocks. In Eindhoven all bonds were made with $\sim 5 \mu$ l bonding solution (Table 4).

Table 4

Blocks bonded with bonding time and the amount of bonding fluid used

\begin{tabular}{llllll}
\hline $\begin{array}{l}\text { Bonded } \\
\text { block }\end{array}$ & Block 1 & Block 2 & Location & $\begin{array}{l}\text { Amount of } \\
\text { solution }(\mu 1)\end{array}$ & Successful \\
\hline VAcvd1 & UAcvd6 & UAcvd7 & Glasgow & 1.4 & Yes \\
VAcvd2 & UAcvd4 & UAcvd8 & Glasgow & 1.4 & Yes \\
VAcvd3 & UAcvd3 & UAcvd3 & Eindhoven & 5 & Yes \\
VAcvd4 & UAcvd1 & UAcvd5 & Eindhoven & 5 & No \\
VA1 & UA4 & UA8 & Glasgow & 1.4 & Yes \\
VA2 & UA3 & UA5 & Glasgow & 1.4 & Yes \\
VA3 & UA1 & UA6 & Eindhoven & 5 & Yes \\
VA4 & UA7 & UA2 & Eindhoven & 5 & Yes \\
VB1 & UB1 & UB2 & Glasgow & 1.4 & Yes \\
VB2 & UB3 & UB4 & Glasgow & 1.4 & Yes \\
VB3 & UB5 & UB6 & Eindhoven & 5 & Yes \\
VB4 & UB7 & UB8 & Eindhoven & 5 & No \\
VC1 & UC1 & UC4 & Glasgow & 2.4 & Yes \\
VC2 & UC2 & UC6 & Glasgow & 2.4 & Yes \\
VC3 & UC3 & UC5 & Eindhoven & 5 & Yes \\
\hline
\end{tabular}




\subsection{Sawing bars}

The sawing of the blocks which was largely unsuccessful. Initially, bonded blocks - VAcvd1, VAcvd2, VA1, VA2, VB1 and VB2 - were sawed simultaneously into bars with dimensions: $45 \mathrm{~mm} \times 10.5 \mathrm{~mm} \times 3.2 \mathrm{~mm}$. The bars were sawn with a speed of $8 \mu \mathrm{m} / \mathrm{stroke}$. After removal from the pan by heating the resin, only 16 bars had survived the sawing of which 7 and 8 bars came from bonded block VA1 and VB2, respectively. All other bars had failed on the bonding surface.

The broken bars were cleaned with alcohol to remove the resin. Next, the bonding surfaces were inspected. Most surfaces appear to have only the $\mathrm{SiO}_{2}$ layers (Fig. 8a). Residuals of the siloxane bond layer did not appear to be present, except on the bars of VB1 and VAcvd2. On them, some small bubbles were visible (Fig. 8b).

\subsection{SEM inspection}

A photograph was taken with a SEM of the bond layer of bar from VB2, which survived the sawing (Fig. 9). The sample has not received any additional treatment (like polishing) to get an optimal image. Because of this and because the bond is not present along the edges, the thickness of the bond layer including the $\mathrm{SiO}_{2}$ layers, could only be estimated at $260 \mathrm{~nm}$. This thickness is in the same order of magnitude as the expected thickness, which was less than $550 \mathrm{~nm}$.

\subsection{Four-point bending}

Due to the fact that the sawing was not totally successful, the four-point bending experiments have not been conducted completely according to the ASTM-norms. The experiments have been performed on 11 bars with a $10 \mathrm{kN}$ tensile testing bench with contact cylinders of $\varnothing 3 \mathrm{~mm}$.

The conditions during measurements were

1. room temperature: $20^{\circ} \mathrm{C}$;

2. outside air pressure: 1003 mbar;

3. $L=40 \mathrm{~mm}$;

4. $l=20 \mathrm{~mm}$;

5. crosshead speed: $0.5 \mathrm{~mm} / \mathrm{min}$; (a)

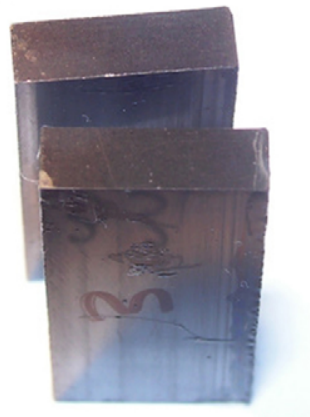

(b)

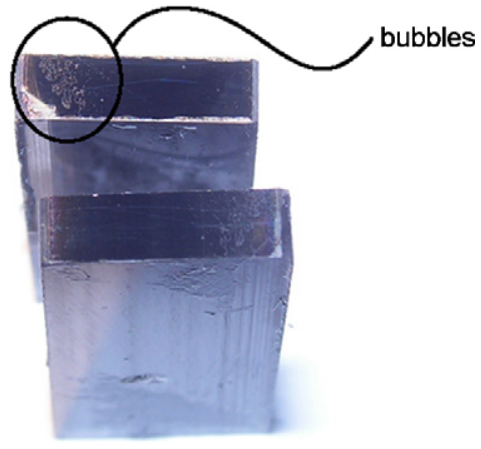

Fig. 8. Bonding surfaces of samples that failed during sawing (a) a bar from block VA2 and (b) a bar of block VAcvd2.

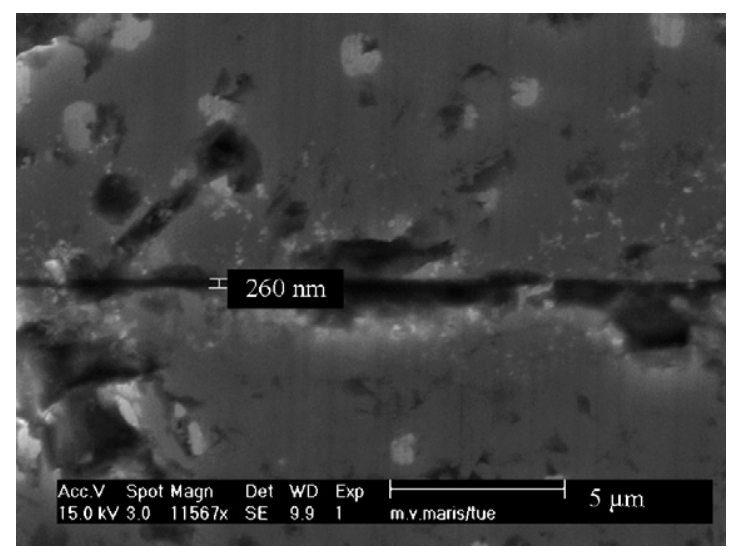

Fig. 9. SEM image of the bond layer of a bar from block VB2.

6. the bars have dimensions: $45 \mathrm{~mm} \times 10.5 \mathrm{~mm} \times 3.2 \mathrm{~mm}$; and

7. eleven bars have been broken.

The results of the experiments are shown in Table 5. The force-time diagrams for two specimens are shown in Fig. 10. The table shows maximum forces that have been measured for the bars from VA1 with an average maximum force of $103.9 \mathrm{~N}$ and a maximum deviation of $7.4 \mathrm{~N}$. This is equivalent with an average strength of $29.3 \mathrm{~N} \mathrm{~mm}^{-2}$ provided that $100 \%$ of the surface has bonded successfully. The maximum forces that have been measured for the bars from VB2 seem to be divided into two groups: one with average $23.1 \mathrm{~N}$ and one with average $48.6 \mathrm{~N}$ corresponding with $6.3 \mathrm{~N} \mathrm{~mm}^{-2}$ and $13.3 \mathrm{~N} \mathrm{~mm}^{-2}$, respectively.

When viewing Fig. 10 one can see that the force does not increase smoothly. This is due to the fact that the specimens have not been ground to remove standing edges in fear of fracture of the bond during grinding. These standing edges fracture first, resulting in a sudden reduction in measured force. The final reduction of the force shows the fracture of the bond.

\section{Discussion}

Every step of the HCB bonding of SiC has been an experiment. This leads to a large number of uncertainties regarding the

Table 5

Results of the bending experiments

\begin{tabular}{lccc}
\hline Bonded block & Bar & $\begin{array}{l}\text { Maximum } \\
\text { force }(\mathrm{N})\end{array}$ & $\begin{array}{l}\text { Maximum stress } \\
\left(\mathrm{N} \mathrm{mm}^{-2}\right)\end{array}$ \\
\hline VB2 & 22 & 23.0 & 6.3 \\
VB2 & 23 & 26.1 & 7.6 \\
VB2 & 24 & 20.2 & 5.4 \\
VA1 & 62 & 109.6 & 30.7 \\
VA1 & 63 & 105.8 & 31.5 \\
VA1 & 64 & 96.4 & 27.0 \\
VB2 & 25 & 57.8 & 15.9 \\
VB2 & 26 & 41.1 & 11.0 \\
VB2 & 27 & 46.9 & 12.9 \\
VA1 & 65 & 97.6 & 27.3 \\
VA1 & 66 & 109.8 & 29.8 \\
\hline
\end{tabular}




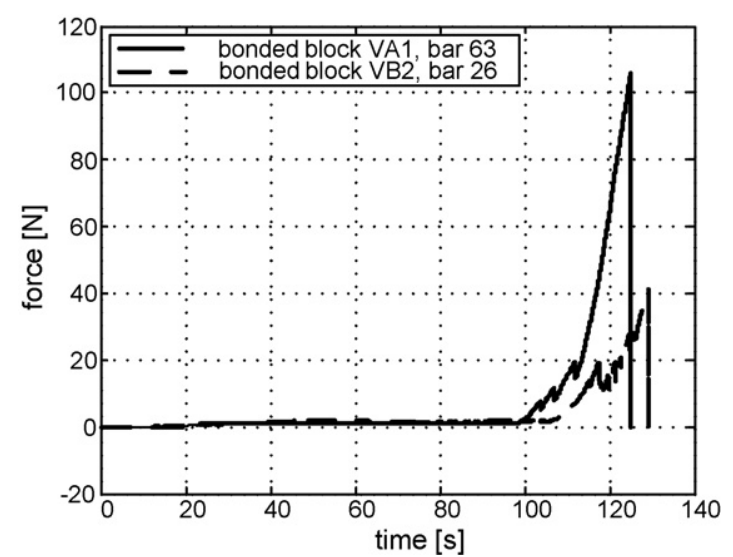

Fig. 10. Force-time diagram of two samples.

fracture of most bars during sawing and measuring the strength of $\mathrm{HCB} \mathrm{SiC}-\mathrm{SiC}$ bonds:

- The bonding surface flatness achieved was not in all cases the desired $\lambda / 10$ PV due to the difficult geometry of the samples. This may have contributed to bonds that are successful over only part of the bonding surface.

- The bonding surface flatnesses achieved, showed different values for the different types of $\mathrm{SiC}$. It is not clear why the flatness of the Boostec blocks was lower than the Xycarb blocks. A possible reason for this might be the fact that Xycarb SiC has a lower Young's modulus. Although the stiffness of the Hexoloy $\mathrm{SiC}$ is approximately equal to the Boostec SiC stiffness, better flatness has likely been achieved because of the more circular polishing pan geometry.

- The oxidization process was not very well controlled. It appears that there is a large dispersion of the $\mathrm{SiO}_{2}$ layers and that the formation of the layers using the wet-oxidization process is sensitive to contamination. This technique has been used because the $\mathrm{SiO}_{2}$ layer have grown in situ from the $\mathrm{SiC}$, making the $\mathrm{SiO}_{2}$ bond to $\mathrm{SiC}$ most probably much stronger than the $\mathrm{HCB}$ bond between the $\mathrm{SiO}_{2}$ layers. However, creating a $\mathrm{SiO}_{2}$ layer using chemical vapour deposition is thought to be weaker but is also considered to be much better controllable. This means that CVD $\mathrm{SiO}_{2}$ can be applied with a controllable and more even thickness, and the process is less sensitive to contamination.

- The bonding process of the 13 blocks that have been bonded successfully, are not a complete success in the sense that the bond may well have occurred over less than $100 \%$ of the bonding surface, due to a lack of flatness of the bonding surfaces, due to contaminations or due to a lack of bonding solution in the interface. The blocks may not have bonded over $100 \%$ of the surface due to the latter argument.

- The differences in the bonding process may have caused differences in the bonds. The bonds made in Glasgow, used filtered bonding fluid to ensure no particulates larger than $0.2 \mu \mathrm{m}$ in diameter were present in the fluid and the volume of solution used was more carefully controlled. This might have led to a higher success rate of the bonds.

- The fracture of the bonds during sawing can be explained by each of the arguments above in combination with two possible properties of the sawing process:

1. During sawing forces are applied to the samples, which cause stresses larger than the strength.

2. The cooling fluid (95\% water) attacks the bond. The argument is that free $\mathrm{OH}^{-}$ions in the water have a tendency to reverse the formation of siloxane chains, thereby reducing the strength of the bond. To test this, four samples that have survived sawing initially, have been subjected to the cooling fluid ( $\mathrm{pH} 7.8$ ) and to a buffer with a $\mathrm{pH}$ of 4.1 for $12 \mathrm{~h}$. After this period the bonds failed at the slightest handling. It is recommended that sawing forces are reduced by using a thinner sawing blade and by reducing the sawing speed and to use an oily cooling fluid.

- The goal of measuring the bond strength has not been met entirely, because only 11 bars could be tested in total, instead of the intended $25 / \mathrm{SiC}$ type. Also because only 11 samples have been tested and because there are too many uncertainties regarding the true bonding surface area, the measured strengths of the bonds in a range of $5-30 \mathrm{~N} \mathrm{~mm}^{-2}$ cannot be subjected to any statistics. What can be said is that the maximum strength of $\sim 30 \mathrm{~N} \mathrm{~mm}^{-2}$ is encouraging. The measured maximum strength is in the region of typical epoxy adhesive bond strengths, which is more than sufficient for the GAIA interferometer system. However, there is no indication that this value is an upper limit for HCB bonding strengths. In silica bonding strengths of more than $50 \mathrm{MPa}$ has been shown, which is the strength of silica. ${ }^{8}$ This should be achievable for $\mathrm{HCB} \mathrm{SiC}-\mathrm{SiC}$ bonds.

\section{References}

1. Rowan, S., Hough, J. and Elliffe, E., Silicon carbide bonding. UK Patent 040 7953.9, 2004. Please contact Mr. D. Whiteford for further information: D.Whiteford@admin.gla.ac.uk.

2. Schwetz, K. A., Silicon carbide based hard materials. In Handbook of Ceramic Hard Materials, Vol. 1, ed. R. Riedel. Wiley-VCH, Weinheim, 2000, ISBN 3-527-29972-6, pp. 683-748.

3. Breysse, J., Castel, B., Laviron, D., Logut, D. and Bougoin, M., All-SiC telescope technology: recent progress and achievements. In Proceedings of the fifth international conference on space optics 2004, 2004, pp. 659671.

4. GAIA SLTRS project team, GAIA System Level Technical Reassessment Study Final Report. Astrium, France, 2002.

5. Gwo, D.-H., Hydroxide-catalyzed bonding. US Patent US 6,548,176 B1, 2003.

6. Gwo, D.-H., Ultra-precision and reliable bonding method. US Patent US 6,284,085 B1, 2001.

7. Rowan, S. and Twyford, S. M., Mechanical losses associated with the technique of hydroxide-catalysis bonding of fused silica. Phys. Lett. A, 1998, 246, 471-478.

8. Elliffe, E. J., Bogenstahl, J., Deshpande, A., Hough, J., Killow, C., Reid, S. et al., Hydroxide-catalysis bonding for stable optical systems for space. Classical Quant. Gravity, 2005, 22, S257-S267.

9. Robertson, D., Killow, C., Ward, H., Hough, J., Heinzel, G., Garcia, A. et al., LTP interferometer-noise sources and performance. Classical Quant. Gravity, 2005, 22, S155-S163. 
10. Heinzel, G., Braxmaier, C., Caldwell, M., Danzmann, K., Draaisma, F., García, A. et al., Successful testing of the LISA Technology Package (LTP) interferometer engineering model. Classical Quant. Gravity, 2005, 22, S149-S154.

11. Reid, S., Cagnoli, G., Elliffe, E. W., Faller, J., Hough, J., Martin, I. et al., Influence of temperature and hydroxide concentration on the set- ting time of hydroxy-catalysis bonds. Phys. Lett. A, 2007, 363, 341345 .

12. ASTM norm C 1161-2C, Standard Test Method for Flexural Strength of Advanced Ceramics at Ambient Temperature. ASTM International, USA, 2006. 